\title{
EGU2020-20706
}

https://doi.org/10.5194/egusphere-egu2020-20706

EGU General Assembly 2020

(c) Author(s) 2020. This work is distributed under

the Creative Commons Attribution 4.0 License.

\section{Offshore 1755 CE Lisbon Tsunami Deposit in the Southern Portuguese Continental Shelf}

\author{
Vincent Kümmerer ${ }^{1}$, Teresa Drago ${ }^{2,3}$, Cristina Veiga Pires ${ }^{1,4}$, Pedro Silva $^{2,5}$, Ana Lopes ${ }^{3}$, Vitor \\ Magalhães ${ }^{2,3}$, Cristina Roque ${ }^{6}$, Ana Isabel Rodrigues ${ }^{3}$, Pedro Terrinha ${ }^{2,3}$, Anxo Mena ${ }^{7}$, Guillermo \\ Francés $^{7}$, Achim Kopf ${ }^{8}$, David Völker ${ }^{8}$, Emília Salgueiro ${ }^{3,9}$, Ana Alberto ${ }^{3,9}$, Cristina Lopes ${ }^{3,9}$, Pedro \\ Costa $^{10}$, and Maria Ana Baptista ${ }^{2,5}$ \\ ${ }^{1}$ Universidade do Algarve, Faro, Portugal \\ ${ }^{2}$ Instituto Dom Luiz, University of Lisbon, Lisbon, Portugal \\ ${ }^{3}$ Instituto Português do Mar e da Atmosfera, Lisbon, Portugal \\ ${ }^{4}$ Centro de Investigação Marinha e Ambiental, Faro, Portugal \\ ${ }^{5}$ Instituto Politécnico de Lisboa, Instituto Superior de Engenharia de Lisboa, Lisbon, Portugal \\ ${ }^{6}$ Estrutura de Missão para a Extensão da Plataforma Continental, Paço d'Arcos, Portugal \\ ${ }^{7}$ University of Vigo, Vigo, Spain \\ ${ }^{8}$ University of Bremen, Bremen, Germany \\ ${ }^{9}$ Centro de Ciências do Mar, Faro, Portugal \\ ${ }^{10}$ Universidade de Coimbra, Departamento de Ciências da Terra, Coimbra, Portugal
}

The importance of tsunami hazard assessment is only possible if a complete dataset of events is available, allowing the determination of the recurrence intervals of the tsunamis adapted to local and regional conditions. One possible way to know these intervals is to study the offshore sedimentary record, looking for sediment remobilised and transported by the incoming tsunami waves and generated backwash currents. Even if these deposits are not of easy access (and not so well studied), the tsunami depositional signature has potential to be better preserved than those located onshore.

A multidisciplinary approach was performed to detect the sedimentary imprints left by the 1755 CE Lisbon tsunami event in three cores located in southern Portuguese continental shelf at water depths between 57 and $91 \mathrm{~m}$. Age models based on ${ }^{14} \mathrm{C}$ and ${ }^{210} \mathrm{~Pb}_{\mathrm{xs}}$ data allowed a probable correspondence with the 1755 CE Lisbon tsunami.

The present study was based in high-resolution analyses using several methodologies such as sand composition, grain size, inorganic geochemistry and microtextural features on quartz grain surfaces. The results yielded evidences for a tsunamigenic origin although no remarkable terrigenous signal is present. Spatial depositional differences of tsunami sediments were detected in the study area by differences in grain size, sand composition and simulated horizontal surface velocities. Also, the heterogeneous and mixing character of the 1755 CE Lisbon offshore tsunami deposits indicate more complex sedimentary conditions compared to the background sedimentation. 
This study shows that in fact the sediment layers corresponding to a tsunami event can be preserved in mid to outer continental shelf environments (other extreme events such as storms were excluded trough hydrodynamic calculations), but its identification and characterization can be done only with a good assemblage of different proxies.

This is a contribution of ASTARTE project (FP7-Grant agreement no: 603839) and CIMA project (UID/MAR/00350/2013). 